\title{
Pregnancy and Marfan syndrome
}

\author{
Sorel Goland ${ }^{1}$, Uri Elkayam ${ }^{2}$ \\ ${ }^{1}$ Heart Institute, Kaplan Medical Center, Rehovot, affiliated to Hebrew University, Jerusalem, Israel; ${ }^{2}$ Department of Medicine, Division of \\ Cardiovascular Disease, and Department of Obstetrics and Gynaecology, Keck School of Medicine, University of Southern California, Los Angeles, \\ CA, USA \\ Correspondence to: Uri Elkayam, MD. LAC/USC Medical Center, 2020 Zonal Avenue, Los Angeles, CA 90033, USA. Email: Elkayam@usc.edu.
}

\begin{abstract}
Pregnancy in women with Marfan syndrome (MFS) presents challenges to the clinician and the patient due to the increased incidence of maternal complications and involvement of the fetus, and deserves special consideration. The leading cause of morbidity and mortality in MFS is aortic dissection. This article presents an extensive review of available clinical information and provides recommendations for the management of patients with MFS during pregnancy.
\end{abstract}

Keywords: Marfan; syndrome; pregnancy; aortic dissection

Submitted Jun 30, 2017. Accepted for publication Oct 16, 2017.

doi: 10.21037/acs.2017.10.07

View this article at: http://dx.doi.org/10.21037/acs.2017.10.07

\section{Introduction}

Marfan syndrome (MFS) is an autosomal dominant hereditary disorder of the connective tissue, in which involvement of the cardiovascular, skeletal, ocular and other systems may be present (1-4). Pregnancy in MFS presents challenges to the clinician and the patient due to the increased incidence of maternal complications and involvement of the fetus, hence deserving special consideration.

\section{Epidemiology and etiology of MFS}

In the United States alone, estimated prevalence of MFS is 1 in 5,000, affecting both genders equally $(2,5)$. Eighty percent of patients have some form of cardiovascular involvement, including aortic dilatation, aortic regurgitation and mitral and tricuspid valve prolapse with or without regurgitation $(2,4,6)$. Although in the past life expectancy was reported to be greatly reduced, significantly better life expectancy due to improved medical and surgical treatment has been recently described (7). The leading cause of morbidity and mortality in MFS is aortic dissection (AoD) $(1,4,8-10)$.

MFS is caused by a mutation in the gene for MFS (FBN1) on chromosome $15 \mathrm{q} 21$, encoding the extracellular matrix protein fibrillin-1 $(1,2)$. Recently, heterozygous mutations have also been identified in the gene encoding tissue growth factor- $\beta$ receptor 2 (TGFBR2) on chromosome 3 p24.2-25 (11). MFS segregates as a dominant trait in 70\% of families and the remainder of cases is caused by de-novo mutations. The diagnosis is based on the Ghent criteria, published in 1996, later revised to take into account many individuals with MFS who do not have the FBN1 mutation (Table 1) $(5,6)$. Major criteria are found infrequently in the general population and therefore carry limited diagnostic sensitivity, but high specificity. The diagnosis may be challenging and should involve a multidisciplinary approach due to multisystem involvement, as well as clinical genetics. Unfortunately, MFS often remains undiagnosed prior to pregnancy and is recognized only after life-threatening complications occur in pregnancy or after the delivery.

\section{Cardiovascular risk of pregnancy in Marfan syndrome}

\section{Risk for the mother}

The most serious complication in patients with MFS is AoD, and the risk is substantially increased during pregnancy and the post-partum period (PP) $(4,8-10,12,13)$. Increased risk is caused by maternal cardiovascular changes such as 


\begin{tabular}{|c|c|c|}
\hline \multirow[t]{5}{*}{ Skeletal } & At least 4 of the following features: & $\begin{array}{l}\text { Two of the major features, or } 1 \text { major feature and } 2 \text { of the } \\
\text { following: }\end{array}$ \\
\hline & Pectus carinatum & Pectus excavatum \\
\hline & Wrist and thumb signs & Characteristic face \\
\hline & Scoliosis $>20^{\circ}$ or spondylolisthesis & \\
\hline & Reduced elbow extension $\left(<170^{\circ}\right)$ & \\
\hline \multirow{2}{*}{ Ocular } & & Increased axial length of globe (causing myopia) \\
\hline & & Hypoplastic iris or ciliary muscle (causing decreased miosis) \\
\hline \multirow[t]{4}{*}{ Cardiovascular } & Dilatation of aortic root & Mitral valve prolapse \\
\hline & & Dilatation of the pulmonary artery, below age 40 \\
\hline & & Calcified mitral annulus, below age 40 \\
\hline & & Other dilatation or dissection of the aorta \\
\hline Pulmonary & None & Spontaneous pneumothorax \\
\hline \multirow{2}{*}{ Genetic findings } & Fibrillin 1 mutation known to cause Marfan syndrome & \\
\hline & $\begin{array}{l}\text { Inheritance of DNA marker haplotype linked to Marfan } \\
\text { syndrome in the family }\end{array}$ & \\
\hline
\end{tabular}

Having one of the features listed constitutes a major criterion or minor criterion for all systems except the skeletal system, where more than one feature is needed. ULSR, upper to lower ratio.

rise in blood volume, heart rate and stroke volume (14) and by hormonally-mediated histologic changes in the diseased aortic wall. Based on two recent systematic reviews $(15,16)$ MFS is still the most frequent cause of pregnancyrelated acute dissections.

Increased risk of complications in pregnant women was initially described by Pyeritz et al. more than 20 years ago, who reported AoD in 20 out of 32 pregnant women with MFS (17). Later, Elkayam et al. (12) reported on 15 additional cases, of which 10 had cardiovascular complications mostly AoD, and mainly in the second and third trimesters, but also few days after conception or during labor and after delivery, including two maternal deaths. Immer et al. (18) described 16 cases of pregnant women with MFS with type A dissection (mean aortic root diameter of $4.8 \pm 0.8 \mathrm{~cm}$ ) with no maternal death, however, 
fetal deaths were reported in three cases. Goland et al. (9) in a review of 39 cases of pregnancy related complications described AoD in 29, involving the ascending aorta (19 cases), descending aorta (8 cases) or both (2 cases), 8 of these women were undiagnosed with MFS prior to the occurrence of aortic complications (9,19-22). Five patients developed an AoD before week 20 of gestation (13-20 weeks), 18 patients at 24-40 weeks, and 6 after delivery. One patient developed an extension of distal dissection at 1 week $\mathrm{PP}$, chronic dissection remained unchanged in two patients and intracranial hemorrhage occurred PP in two cases. Nineteen of the patients were diagnosed with dilatation of aorta prior to pregnancy and four had a history of aortic surgery. Maternal and fetal mortality were reported in two patients, and fetal loss in two cases despite of maternal survival. Reviewing the English literature between 1995 and May 2017 (23-35), we found 38 additional MFS cases with pregnancy-related complications (36-52). Sixty-three women developed an acute AoD: $59 \%$ of the ascending aorta, $32 \%$ of the descending aorta and both in $9 \%$. Vast majority occurred after 24 weeks gestation (61\%) or up to 3 months postpartum (23\%) and the rest between 7-23 weeks. In addition, 8 patients developed progressive dilatation of the ascending aorta requiring surgery during pregnancy. In two women with chronic distal dissection, it remained stable during pregnancy in one and extended 1 week postpartum in the other. Three patients experienced intracranial hemorrhage postpartum (30 min, 6 weeks and 57 days after delivery). Maternal mortality was reported in 7 out of 73 cases with available outcome information, 3 died from immediate complications of AoD and 4 had delayed death from 2 months to 8 years (1 patient each from intracranial hemorrhage, subarachnoid hemorrhage, recurrent AoD and SBE). Three cases of severe morbidity were reported: one of paraplegia after aortic repair due to type $\mathrm{B}$ dissection and two with multi-organ failure, requiring ECMO support in one. Majority of the patients in whom a dissection occurred during pregnancy delivered their babies by $\mathrm{C}$-section. Information regarding the time of surgery was available in 50 patients and was prior to delivery in 8 women, immediately after C-section in 22 and hours to 1 month after delivery in the rest of the patients.

The incidence of pregnancy-related AoD in patients with MFS has varied among available publications and most reports have described severe complications. This information however, is likely to provide an over representation of pregnancy-related complications caused by a bias toward reporting complicated rather than uncomplicated cases. Such an assumption is supported by several reports of significantly lower rate of complications. Pyeritz et al. (17) showed only a low risk for maternal complications and death in a retrospective analysis of 105 pregnancies in 26 patients with MFS and a prospective follow-up of 10 patients who had minimal or no pre-existing cardiovascular disease. Rossiter et al. (19) prospectively evaluated 45 pregnancies in 21 women with MFS and reported AoD in only 2 cases (4.4\%) while the rest who had aortic diameter $<4.0 \mathrm{~cm}$ tolerated pregnancy well. More recently, Lipscomb et al. (20) reported the outcome of 91 pregnancies in 36 women with MFS and described AoDs in pregnancy in 4 (4.4\%) with two others requiring aortic surgery following delivery. Meijboom et al. (53), followed prospectively 127 women with MFS and compared aortic root diameter changes during 33 pregnancies with those of 22 matched childless women. During 6.4 years of follow-up, no significant difference in growth of the aortic root was obtained and only one woman with previous type A dissection developed type B dissection during her $2^{\text {nd }}$ pregnancy. The authors concluded that pregnancy is relatively safe in women with an aortic root diameter of $<4.0 \mathrm{~cm}$. In a retrospective French study Pacini et al. (54) reported 7 aortic complications in 85 women (160 pregnancies; $4 \%$ ) representing a 5 fold increase in risk of pregnancy related aortic complication compared to that of a group of never pregnant women with MFS. Omnes et al. (41) from the same group reported good outcome in 17 women followed prospectively and closely during pregnancy, and an additional case of acute AoD who was referred at the late pregnancy ( 37 weeks) with an increase in the aortic diameter from 47 to $50 \mathrm{~mm}$ between weeks 24 and 37 of pregnancy. Donnelly et al. (55) reported on a cohort of 69 women with MFS, without pregnancy-related AoD. Kuperstein et al. (51) reported on 2 cases of postpartum AoD in a cohort of 19 women with MFS (6.5\%), 1 case of type A dissection in a woman with a dilated aortic root who declined $\beta$-blockers and 1 case of type $B$ dissection. Hassan et al. (56) in a large, population-based US cohort reported on 339 pregnant women with MFS describing 6 pregnancyrelated AoDs (1.8\%) and 1 related death. The most recent large longitudinal observational study (GenTAC) published by Roman et al. (57) reported outcomes of 227 pregnancies in 97 women. Pregnancy-related aortic complications occurred in 10 women (4.4\%); AoD in 8 , coronary artery dissection in 1 and aortic growth $>3 \mathrm{~mm}$ in 2 . However, information on the aortic size before pregnancy was not available. 
Several studies focused on the potential growth of the aorta in pregnant women with MFS and have reported contradictory results $(19,22,51,53,55)$. Rossiter et al. (19) prospectively evaluated 45 pregnancies in 21 women with MFS and found AoD in only 2 while the remaining women with an aortic diameter $<40 \mathrm{~mm}$ tolerated pregnancy well without an increase in aortic diameter. Meijboom et al. (53) found no significant difference in the aortic root growth during 33 pregnancies in 23 patients with MFS (aortic diameter $\leq 45 \mathrm{~mm}$ ), compared to 22 matched childless women in a 6.4-year follow-up. In contrary, Donnelly et al. (55) described 199 pregnancies in 98 MFS women, there were no acute AoD, but 2 women, developed symptomatic carotid artery dissections. An average increase of $3 \mathrm{~mm}(0-7 \mathrm{~mm})$ in aortic diameter was observed during pregnancy, which was decreased postpartum, but without complete recovery at 5 years follow-up. The prevalence of both AoD and elective aortic surgery during long-term follow-up was higher in women with prior pregnancy, larger aortic diameter, greater rate of aortic growth during pregnancy, increased number of pregnancies, and no $\beta$-blocker therapy and regular follow-up during pregnancy.

In summary, the rates of aortic complications reported in prospective studies appear to reach on average $4.0 \%$ $(3,19,41,53)$ and is $2-6 \%$ in large retrospective reports including 1,142 pregnancies (20,22,53-58). The expected rate of AoD is ranging from $1 \%$ in women with aortic diameter $<40 \mathrm{~mm}$ to as much as $10 \%$ in high-risk patients (those with aortic root diameter $>40 \mathrm{~mm}$, rapid dilatation or previous dissection of the ascending aorta) $(3,9,53,59)$. Despite the rare occurrence of AoD in women with MFS and a normal size aorta $(3,9,18,59,60)$, an event-free pregnancy cannot be guaranteed in these women as well $(19,20,61,62)$. Although AoD occurs in most women during the third trimester and the PP, it may also occur at any time of gestation $(8,9,59)$.

\section{Long-term outcome after pregnancy}

Information regarding expected morbidity and mortality after pregnancy should be provided to a woman with MFS who is considering pregnancy. Groenink et al. (60) reported 5 - and 10-year survival after diagnosis of $95 \%$ and $88 \%$ respectively and complication free survival of $78 \%$ and $66 \%$. Ten percent of the patients developed dissection and $24 \%$ underwent prophylactic repair. In patients without aortic complications, mean aortic root diameter was $33 \mathrm{~mm}$ and aortic root growth was $0.5 \mathrm{~mm} /$ year. In patients who underwent prophylactic aortic root surgery, mean aortic root diameter was $49 \mathrm{~mm}$ and aortic growth $3.6 \mathrm{~mm}$ /year. One patient (3\%) died post operatively and 10\% developed complications at other levels of the aorta. Of the 13 patients who developed AoD, 9 died either before reaching the hospital or perioperatively. Svensson et al. (63) and Gott et al. (64) reported on a total of 393 patients who underwent aortic surgery for aortic root replacement. Mortality was higher in patients who had urgent or emergent operation. These data clearly indicate that in spite of effective medical and surgical therapy, MFS is associated with increased likelihood of major morbidity and even premature death that also applies to women after successful delivery. The likelihood of such complications is especially high in patients with a history of acute type A dissection but unexpected fatal complications may also occur following prophylactic aortic root or mitral valve surgery $(52,53,63)$.

\section{Risk for the fetus and obstetric complications}

The risk of transmission of MFS to the offspring appears to be at least $50 \%$. Because of the variability in clinical presentation, severe expression of the syndrome can occur in an offspring of a mother with a relatively mild presentation. It should be noted that development of AoD in the mother carries a substantial risk to the fetus $(8,9,12,18)$. Among 71 cases with available information in our review of literature, fetal loss occurred in 7 pregnancies, and stillbirth and brain atrophy in 1 each. Fetal loss was due to termination of pregnancy prior to aortic repair in 2 cases, intrauterine death in 3 (17-24 weeks) and fetal loss as a result of maternal death in 2 .

Pregnancy in women with MFS has been shown to be associated with a high rate (up to $40 \%$ ) of obstetric complications, such as premature delivery, mainly due to premature rupture of membranes, intrauterine growth restriction, small for gestational age and neonatal mortality $(8,9,22,41,51,56,65,66)$.

\section{Prenatal diagnosis of Marfan syndrome}

Molecular genetic testing can be used for the prenatal diagnosis of MFS (67-69). It can be accomplished by chorionic villus sampling or amniocentesis in affected families. In addition to prenatal diagnosis, preimplantation diagnosis using in vitro fertilization is possible when the parent's mutation is known. In addition to the genetic testing, which can be done in early gestation, 
echocardiography may be used in the $3^{\text {rd }}$ trimester to diagnose cardiac manifestations of MFS in the fetus.

\section{Preconception counseling}

Unfortunately, based on previous published data, preconception counseling in women with known MFS is often not done and in many cases the syndrome is diagnosed for the first time during pregnancy or the PP following the development of complications (22). Pacini et al. (54) reported seven aortic complications in 160 pregnancies in women with MFS (4\%). Diagnosis of MFS was made during pregnancy in three women, at time of surgery in two other women, and as late as 2 years after surgery in the last two patients. As a result, of late diagnosis none of these women was followed as recommended and/or treated with $\beta$-blockers. In line with these studies our review of published literature from 2009 indicated that almost half of the pregnant women were diagnosed with MFS only after occurrence of aortic complications (8).

The management of pregnancy in women with MFS should ideally be started prior to conception. The maternal and fetal risk should be assessed and discussed by a multidisciplinary team including a cardiologist, obstetrician and genetic specialist (59). Women should be counseled about potential pregnancy-related complications and should also be informed about the possibility of prenatal diagnosis using both genetic testing and fetal echocardiography (68-70). Prenatal genetic testing could be used in cases when the result will guide parent's decisions regarding either continuation or termination of pregnancy.

During the preconception consultation, the woman and her family should be informed about possible morbidity during and after pregnancy. The patient should undergo careful evaluation for all cardiovascular abnormalities including valvular pathology, left ventricular function, diameter of the aortic root and the ascending and descending aorta using transthoracic and when needed transesophageal echocardiogram $(8,9,59)$. Evaluation of the distal aorta is especially important in patients with dilated proximal aorta and those with the history of surgical repair of the proximal aorta, who have been shown to be at increased risk of distal AoD (71,72). Either computed tomography (CT) or magnetic resonance imaging (MRI) can be used for a precise assessment of the aortic size and anatomy before pregnancy $(59,72,73)$. Expected risk of aortic complications can be estimated based on the presence of aortic root dilatation $(>4.0 \mathrm{~cm})$, rapid increase in aortic diameter or previous dissection of the ascending aorta $(18,19,59,74)$. Patients should also informed that dissection in pregnant women with normal sized aortas have been reported $(20,61)$, indicating that event-free pregnancy cannot be guaranteed to any patient with MFS and that AoD can occur in any stage of gestation as well as in the PP period. Most often AoD occurred in MFS women in their $3^{\text {rd }}$ decade of life, it is advisable therefore, to plan a pregnancy at a younger age $(7,18)$. Patients should be told of the need for a close follow up and treatment with a high dose beta-blockers during pregnancy and the PP period $(8,10,59)$ and be educated of symptoms related to AoD and the need for an immediate care. In addition, women should be informed that previous aortic surgery cannot guarantee uneventful pregnancy and cannot eliminate the risk of recurrent dissection in other parts of the aorta. Elective aortic root replacement can be performed with low morbidity and mortality $(64,75,76)$. For this reason, women with MFS with indications for elective surgery should undergo aortic root replacement prior to pregnancy $(10,74)$.

\section{Surgical treatment and pregnancy}

\section{Preventive aortic surgery before pregnancy}

The 2011 European Society of Cardiology (ESC) guidelines on management of cardiovascular disease during pregnancy call for prophylactic elective surgery to prevent AoD in women with MFS contemplating pregnancy with aortic root dilatation $>45 \mathrm{~mm}$, with the proviso that there is still a risk of dissection even after surgery (59). In patients with aortic diameter of $40-45 \mathrm{~mm}$, considerations for surgical intervention were recommended in cases with rapid growth and a family history of premature AoD. The 2010 American guidelines recommend avoiding pregnancy or attempting aortic root replacement before pregnancy if the aortic root is $>40 \mathrm{~mm}$ (73), and the recent [2014] Canadian Cardiovascular Society guidelines recommend prophylactic aortic replacement at an aorta diameter $>40 \mathrm{~mm}$ with or without additional risk factors (77). Although previous studies reported favorable maternal and fetal outcomes during pregnancy with aortic enlargement $<45 \mathrm{~mm}$, stricter recommendations by American and Canadian guidelines are probably based on the fact that there is no completely safe aortic root diameter in pregnancy $(8,18-20)$ and the suggestion of some investigators of reducing the threshold for elective aortic root replacement in non-pregnant women compared to men (53) and by others of using an indexed 
adusted aortic diameter for BSA of $2.75 \mathrm{~cm} / \mathrm{m}^{2}$ in small women as a threshold for surgery $(72,78)$.

A valve-sparing aortic root replacement (the David's and Yacoub's procedures) in patients with anatomically normal valves has been advocated in patients with MFS $(73,79,80)$. Although long-term survival has been favorable and the rate of complications low, the durability of this procedure may be somewhat limited, with $17-20 \%$ of patients requiring re-operation by 10 years (81). Thus, this technique can be a reasonable alternative for pregnant women and women in the child bearing age who are planning pregnancies and are willing to accept the risk of possible re-operation in the future.

\section{Surgery for aortic complication during pregnancy}

Cardiac surgery during pregnancy is associated with high risk to the fetus and could also increase the risk to the mother. Recent publication describing urgent open heart surgery for severe valvular disease in 12 pregnant women with MFS reported maternal mortality of $8.7 \%$ and extremely high intrauterine death (10 out of 12) (82). Yates et al. (48) reported in 2015 on a series of 11 women who had aortic surgery including aortic root and/or valve replacement during pregnancy (median gestational age 19 weeks) without maternal death, but high fetal mortality of $27 \%$. Another recent data suggests low maternal mortality $(1.47 \%)$ similar to that associated with nonemergent cardiac surgery in non-pregnant women (83).

Since the risk associated with emergency operations for AoD or rupture is high, a progressive $>5 \mathrm{~mm}$ dilation of the aorta during pregnancy has also been proposed to mandate an elective surgery either after a therapeutic abortion (up to 20 weeks) or during pregnancy $(8,59,62,83)$. Successful surgery during gestation or shortly after delivery has been described in a number of women for a marked dilatation of the aorta and for $\operatorname{AoD}(14,18,21,48,61,83)$. Because of the increased fetal loss associated with cardiac surgery during pregnancy $(9,18,48,61,83-85)$, a C-section should be done before or concomitantly with thoracic surgery in cases where fetal maturity can be confirmed $(17,18,59)$. Termination of pregnancy should be considered when AoD occurs early taking in account a significant risk of fetal complication and loss (48). In our review of literature out of seven cases of fetal mortality it was reported early (before 20 weeks of gestation) in 4: due to termination of pregnancy in 2 (1 hysterectomy, 1 elective abortion) and due to intrauterine fetal death in 2 women.
Optimal perioperative management including full maternal and fetal monitoring, attention to cardiopulmonary bypass, pulsatile perfusion, near-normothermia, maintenance of high flow rate $\left(>2.5 \mathrm{~L} / \mathrm{min} / \mathrm{m}^{2}\right)$ and mean blood pressure $>70 \mathrm{mmHg}$, hematocrit $>28 \%$, avoidance of maternal hypoglycemia and hypoxia, placing the patient in the lateral position during $\mathrm{CPB}$ to avoid inferior vena cava compression and avoidance of vasoconstrictors, all have been reported to decrease risks for both the mother and the baby $(48,82-84)$.

Recently the thoracic endovascular aortic repair has been introduced for the management of patients with type B AoD. Data from the International Registry of Acute AoD have suggested a lower mortality over a 5 -year period associated with this technique compared with medical therapy (86). Only limited information from isolated case reports is however, available on the use of this technique as a bridge to open surgery in pregnant women with MFS.

\section{Medical therapy}

A number of studies have demonstrated that $\beta$-blockers slow the growth of the aortic root and significantly reduce rates of aortic dissection and death $(55,87)$. However, a recent meta-analysis of all prospective trials demonstrated that although $\beta$-blockers were effective in aortic root growth rate reduction in patients with MFS, they had no influence on rate of dissection and final aortic size (88). The applicability of these findings to pregnancy, which is associated with changes in the aortic wall and enhanced risk of dissection, needs to be studied in more detail, but on the basis of available information, the prophylactic use of $\beta$-blockers during pregnancy seems to make a good clinical sense. The use of selective $\beta$ receptor blockers is recommended during pregnancy at a dose titrated to reduce heart rate by at least $20 \mathrm{bpm}$ with a close followup to detect intra-uterine growth restriction $(8,10,13,59)$. A favorable effect of angiotensin receptor blockers (ARB) leading to a reduction in rate of progressive aortic root dilation in patients with MFS has been reported. The use of ARBs in pregnancy, however, is contraindicated because of potential toxicity to the fetus (89), therefore, ARB's should be switched to $\beta$-blockers as soon as contraceptives are stopped and pregnancy is planned. As high blood pressure may increase the risk of aortic complications, strict blood pressure control is recommended for all pregnant women with MFS. The use of nitroprusside for acute AoD during pregnancy may lead to thiocyanate toxicity to the fetus, thus, the gestational use of nitroglycerine or 
hydralazine plus $\beta$-blockers to control blood pressure is preferred. The use of $\beta$-blockers in patients with chronic type $\mathrm{B}$ dissection has been shown to reduce the progression of aortic dilatation, hospitalizations and additional aortic procedures (90).

\section{Follow-up during pregnancy and postpartum}

Patients with MFS should be followed during pregnancy by their obstetrician and cardiologist in collaboration. Transthoracic echocardiography (TTE) examination should be performed every 4-6 weeks in patients with aortic diameter of $\geq 40 \mathrm{~mm}$, progressive dilation and each trimester in those with normal-sized aorta (59). The American guidelines (ACCF/AHA) recommend monthly or bimonthly echocardiographic measurements of the ascending aortic dimensions in women with aortic dilatation during pregnancy and the first weeks after delivery (73). Postpartum AoD has been described in 16 out of 62 cases reviewed by us $(26 \%)$ with the latest occurring 4 months after the delivery. Similar findings were reported by Yuan et al. (16) who published a literature review of 27 cases of postpartum dissection which occurred from day 1 to day 42 and $41 \%$ of them accounted for MFS. Based on this information it seems advisable to extend the follow up of women with MFS for 3-6 months post-partum.

Careful examination, with special attention in order to obtain reproducible serial measurements of all visible parts of the aorta, is critically important for accurate assessment and early detection of important changes in aortic dimensions and at the same time the prevention of false diagnosis of enlargement of aortic diameter (91) which can lead to unnecessary premature delivery and/ or surgery. In those with suboptimal TTE visualization, TEE or MRI can be used for assessment (59). Magnetic resonance imaging without gadolinium is considered safe during pregnancy (92).

\section{Labor and delivery}

Vaginal delivery is considered safe in patients with MFS who have an aortic diameter of $<40 \mathrm{~mm}(20,59,62)$. In these patients, C-section should be reserved for obstetrical indications $(12,20,62)$. At the same time, however, to reduce the stress of labor, epidural anesthesia and $\beta$-blockers or vasodilators should be used to minimize pain and hemodynamic fluctuation during labor and delivery (14) and forceps or vacuum to shorten the second stage of labor are recommended. It should be noted that lumbosacral dural ectasia is present in about $70 \%$ of patients with MFS, anesthesia consultation is therefore advisable planning of the appropriate anesthesia prior to delivery (1).

Patients with aortic dilatation $\geq 40 \mathrm{~mm}$ or with progressive dilatation of aorta during pregnancy are at high risk for AoD and elective $\mathrm{C}$-section, with epidural anesthesia is preferred to minimize the hemodynamic changes, especially blood pressure peaks associated with vaginal delivery that can induce dissection. When progressive dilatation of aorta occurs early in pregnancy before the fetus is viable, aortic repair with fetus in-utero or termination of pregnancy prior to surgery should be considered. In the case of an urgent need for surgery (type $\mathrm{A} A \mathrm{AoD}$, progressive dilatation) later in pregnancy to prevent an unfavorable fetal outcome, emergency delivery of the fetus by a C-section should be considered, followed directly by cardiac surgery $(8,12,59,61)$. If all possible cardiac surgery should be performed in a hospital with a neonatal intensive care facility. If elective aortic repair is indicated in the later stage of pregnancy, surgery should be performed, if possible, a few days after delivery (18). Postpartum hemorrhage of the uterine vasculature has been reported in women with MFS and should be anticipated $(65,66)$. Due to increased risk of dissection postpartum, weekly clinical follow-up for high risk patients and monthly for low risk should be considered during at least 4-6 months after delivery $(59,62,73)$. Losartan is not recommended for use during pregnancy. Because of its low molecular weight, excretion into breast milk is to be expected. There are no available reports on the use of the drug during human lactation and the effect on the nursing infant is unknown (93). Because of this beta blocker therapy should be continued for the lactating period.

The key recommendations for the management of pregnancy in women with MFS are presented in Tables 2,3. 
Table 2 Pregnancy management in women with Marfan syndrome

\begin{tabular}{|c|c|c|}
\hline Time & Recommendations & Special consideration \\
\hline \multirow[t]{6}{*}{ Preconception } & To assess maternal and fetal risks: & \multirow{4}{*}{$\begin{array}{l}\text { Multidisciplinary care involving cardiologists, } \\
\text { obstetricians, genetic specialists }\end{array}$} \\
\hline & Past medical and family history & \\
\hline & Information on the aortic size before conception & \\
\hline & To provide proper information on possible prenatal diagnosis & \\
\hline & Initiation of $\beta$-blockers & Stop ARB when contraception is stopped \\
\hline & Consider elective surgery when ascending aorta $\geq 45 \mathrm{~mm}$ & $\begin{array}{l}\text { Significant AR or MR with LV depression, according to } \\
\text { the guidelines for valvular disease }\end{array}$ \\
\hline \multirow[t]{8}{*}{ During pregnancy } & $\begin{array}{l}\text { Serial TTE } 4-12 \text { weeks depends on the size of ascending } \\
\text { aorta (timing see Table } 3 \text { ) }\end{array}$ & $\begin{array}{l}\text { Use TEE and MRI without gadolinium when needed for } \\
\text { optimal visualization }\end{array}$ \\
\hline & Continue $\beta$-blockers & Strict control of BP \\
\hline & Type A aortic dissection: & \multirow{6}{*}{$\begin{array}{l}\text { Multidisciplinary care management including } \\
\text { obstetricians, fetal care, cardiothoracic/vascular } \\
\text { surgeon and anesthetists. Optimal perioperative } \\
\text { management including full maternal and fetal } \\
\text { monitoring, attention to cardiopulmonary bypass, } \\
\text { pulsatile perfusion, etc. Serial assessment of the aorta } \\
\text { with MRI without gadolinium, thoracic endovascular } \\
\text { aortic repair can be considered in selected cases by an } \\
\text { experienced team }\end{array}$} \\
\hline & Unurgent surgery is required & \\
\hline & Viable fetus: c/s followed by aortic surgery & \\
\hline & Non-viable fetus: aortic surgery with fetus-in-uterus & \\
\hline & Type B dissection: & \\
\hline & Conservative treatment with attention to fetal monitoring & \\
\hline Delivery & $\begin{array}{l}\text { C-section with the ascending aorta } 40-45 \text { and }>45 \mathrm{~mm} \text {, } \\
\text { vaginal delivery in women with diameter }<40 \mathrm{~mm}\end{array}$ & Timely diagnosis and management of $\mathrm{PPH}$ \\
\hline
\end{tabular}

\begin{tabular}{|c|c|c|}
\hline \multirow[t]{3}{*}{ Postpartum } & $\begin{array}{l}\text { Continue } \beta \text {-blockers } \\
\text { Clinical aortic follow-up during at least } 2 \text { months (up to } \\
6 \text { moths) }\end{array}$ & \multirow[t]{3}{*}{$\begin{array}{l}\text { Women's education is essential: to seek immediate } \\
\text { medical attention when symptoms of aortic dissection } \\
\text { occur }\end{array}$} \\
\hline & High risk-weekly & \\
\hline & Low risk-monthly & \\
\hline
\end{tabular}




\begin{tabular}{|c|c|c|}
\hline Aortic size (mm) & Follow-up & Delivery \\
\hline$<40$ & Follow-up monthly & Vaginal \\
\hline $40-45$ & Follow-up monthly & Cesarean section \\
\hline$\geq 45$ & $\begin{array}{l}\text { Prophylactic surgery pre- } \\
\text { pregnancy/or during } \\
\text { pregnancy in women with } \\
\text { rapid growth of the aorta }\end{array}$ & Cesarean section \\
\hline
\end{tabular}

\section{Acknowledgements}

None.

\section{Footnote}

Conflicts of Interest: The authors have no conflicts of interest to declare.

\section{References}

1. Judge DP, Dietz HC. Marfan's syndrome. Lancet 2005;366:1965-76.

2. Pepe G, Giusti B, Sticchi E, et al. Marfan syndrome: current perspectives. Appl Clin Genet 2016;9:55-65.

3. Rossiter JP, Johnson TR. Management of genetic disorders during pregnancy. Obstet Gynecol Clin North Am 1992;19:801-13.

4. von Kodolitsch Y, Robinson PN. Marfan syndrome: an update of genetics, medical and surgical management. Heart 2007;93:755-60.

5. Loeys BL, Dietz HC, Braverman AC, et al. The revised Ghent nosology for the Marfan syndrome. J Med Genet 2010;47:476-85.

6. De Paepe A, Devereux RB, Dietz HC, et al. Revised diagnostic criteria for the Marfan syndrome. Am J Med Genet 1996;62:417-26.

7. Silverman DI, Burton KJ, Gray J, et al. Life expectancy in the Marfan syndrome. Am J Cardiol 1995;75:157-60.

8. Goland S, Elkayam U. Cardiovascular problems in pregnant women with marfan syndrome. Circulation 2009;119:619-23.

9. Goland S, Barakat M, Khatri N, et al. Pregnancy in Marfan syndrome: maternal and fetal risk and recommendations for patient assessment and management. Cardiol Rev 2009;17:253-62.
10. Elkayam U, Goland S, Pieper PG, et al. High-Risk Cardiac Disease in Pregnancy: Part I. J Am Coll Cardiol 2016;68:396-410.

11. Mizuguchi T, Collod-Beroud G, Akiyama T, et al. Heterozygous TGFBR2 mutations in Marfan syndrome. Nat Genet 2004;36:855-60.

12. Elkayam U, Ostrzega E, Shotan A, et al. Cardiovascular problems in pregnant women with the Marfan syndrome. Ann Intern Med 1995;123:117-22.

13. Elkayam U, Ostrzega E, Shotan A, et al. Marfan Syndrome in Pregnancy. Cardiac Problems in Pregnancy. New York: Wiley-Liss, 1998:211-21.

14. Elkayam U, Gleicher, N. Hemodynamics and cardiac function during normal pregnancy and the puerperium. Cardiac Problems in Pregnancy. New York: Wiley-Liss, 1995:23-32.

15. Rajagopalan S, Nwazota N, Chandrasekhar S. Outcomes in pregnant women with acute aortic dissections: a review of the literature from 2003 to 2013. Int J Obstet Anesth 2014;23:348-56.

16. Yuan SM. Aortic dissection during pregnancy: a difficult clinical scenario. Clin Cardiol 2013;36:576-84.

17. Pyeritz RE. Maternal and fetal complications of pregnancy in the Marfan syndrome. Am J Med 1981;71:784-90.

18. Immer FF, Bansi AG, Immer-Bansi AS, et al. Aortic dissection in pregnancy: analysis of risk factors and outcome. Ann Thorac Surg 2003;76:309-14.

19. Rossiter JP, Repke JT, Morales AJ, et al. A prospective longitudinal evaluation of pregnancy in the Marfan syndrome. Am J Obstet Gynecol 1995;173:1599-606.

20. Lipscomb KJ, Smith JC, Clarke B, et al. Outcome of pregnancy in women with Marfan's syndrome. Br J Obstet Gynaecol 1997;104:201-6.

21. Zeebregts CJ, Schepens MA, Hameeteman TM, et al. Acute aortic dissection complicating pregnancy. Ann Thorac Surg 1997;64:1345-8.

22. Lind J, Wallenburg HC. The Marfan syndrome and pregnancy: a retrospective study in a Dutch population. Eur J Obstet Gynecol Reprod Biol 2001;98:28-35.

23. McDermott CD, Sermer M, Siu SC, et al. Aortic dissection complicating pregnancy following prophylactic aortic root replacement in a woman with Marfan syndrome. Int J Cardiol 2007;120:427-30.

24. Seeburger J, Mohr FW, Falk V. Acute type A dissection at 17 weeks of gestation in a Marfan patient. Ann Thorac Surg 2007;83:674-6.

25. Wakiyama H, Nasu M, Fujiwara H, et al. Two surgical cases of acute aortic dissection in pregnancy with marfan 
syndrome. Asian Cardiovasc Thorac Ann 2007;15:e63-5.

26. Pagni S, Ganzel BL, Tabb T. Hemiarch aortic replacement for acute type A dissection in a Marfan patient with twin pregnancy. Interact Cardiovasc Thorac Surg 2008;7:740-1.

27. Shihata M, Pretorius V, MacArthur R. Repair of an acute type A aortic dissection combined with an emergency cesarean section in a pregnant woman. Interact Cardiovasc Thorac Surg 2008;7:938-40.

28. Ibrahim MF, Refaat AA. eComment: acute type A aortic dissection at seven weeks of gestation in a Marfan patient. Interact Cardiovasc Thorac Surg 2008;7:940.

29. Espinoza SC, Selman AR, Pauchard TF, et al. Acute type A aortic dissection in pregnant patient with Marfan syndrome. Report of one case. Rev Med Chil 2009;137:98-100.

30. Saeki N, Taguchi S, Kawamoto M. Successful management of a patient with Marfan syndrome complicated with acute aortic dissection using landiolol during Cesarean section. J Anesth 2010;24:277-9.

31. Mendoza-Alvarez SA, Fuentes-León J, Vargas-Ayala G, et al. Marfan's syndrome presented with dissected thoracoabdominal aneurism and pregnancy. A case report. Rev Med Inst Mex Seguro Soc 2009;47:669-72.

32. Haas S, Trepte C, Rybczynski M, et al. Type A aortic dissection during late pregnancy in a patient with Marfan syndrome. Can J Anaesth 2011;58:1024-8.

33. Vranes M, Velinovic M, Kovacevic-Kostic N, et al. Pregnancy-related aortic aneurysm and dissection in patients with Marfan's syndrome: medical and surgical management during pregnancy and after delivery. Medicina (Kaunas) 2011;47:604-6.

34. Goya M, Alvarez M, Teixido-Tura G, et al. Abdominal aortic dilatation during pregnancy in Marfan syndrome. Rev Esp Cardiol (Engl Ed) 2012;65:288-9.

35. Nonga BN, Pasquet A, Noirhomme P, et al. Successful bovine arch replacement for a type A acute aortic dissection in a pregnant woman with severe haemodynamic compromise. Interact Cardiovasc Thorac Surg 2012;15:309-10.

36. Chang CY, Yang JM, Lam CW, et al. Successful management of aortic dissection in a patient with Marfan syndrome during pregnancy. Am J Obstet Gynecol 2013;208:e3-6.

37. Lee SS, Jung TE, Lee DH. Acute Type II Aortic Dissection with Severe Aortic Regurgitation and Chronic Descending Aortic Dissection in Pregnant Patient with Marfan Syndrome. Korean J Thorac Cardiovasc Surg 2012;45:404-7.
38. Allyn J, Guglielminotti J, Omnes S, et al. Marfan's syndrome during pregnancy: anesthetic management of delivery in 16 consecutive patients. Anesth Analg 2013;116:392-8.

39. Master M, Day G. Acute aortic dissection in pregnancy in a woman with undiagnosed marfan syndrome. Case Rep Obstet Gynecol 2012;2012:490169.

40. Katsuragi S, Neki R, Yoshimatsu J, et al. Acute aortic dissection (Stanford type B) during pregnancy. J Perinatol 2013;33:484-5.

41. Omnes S, Jondeau G, Detaint D, et al. Pregnancy outcomes among women with Marfan syndrome. Int J Gynaecol Obstet 2013;122:219-23.

42. Kulikowski JD, Colman JM, Silversides CK, et al. Postpartum type B aortic dissection in Marfan syndrome. Ann Thorac Surg 2013;96:705.

43. Tang GH, Malekan R, Lansman SL, et al. Aortic valvesparing reimplantation and mitral repair in a pregnant, second trimester Marfan patient: surgical decision. Ann Thorac Surg 2013;95:701-3.

44. Sterner D, Probst C, Mellert F, et al. Surgical treatment and thoracic endovascular aortic repair in type A aortic dissection in a pregnant patient with Marfan syndrome. Ann Vasc Surg 2014;28:1317.e7-10.

45. Sato A, Ishida M, Ishibashi K, et al. A case of acute aortic dissection in a woman with Marfan syndrome at 29 weeks' gestation. J Obstet Gynaecol 2014;34:358.

46. Kim SW, Kim D, Hong JM. Acute aortic dissection in pregnancy with the marfan syndrome. Korean J Thorac Cardiovasc Surg 2014;47:291-3.

47. Liu H, Shu C, Li X, et al. Endovascular aortic repair combined with chimney technique in the treatment of stanford type B aortic dissection involving aortic arch. Ann Vasc Surg 2015;29:758-63.

48. Yates MT, Soppa G, Smelt J, et al. Perioperative management and outcomes of aortic surgery during pregnancy. J Thorac Cardiovasc Surg 2015;149:607-10.

49. Uozaki N, Mizuno K, Shiraishi Y, et al. Anesthetic Management of a Patient Complicated with Marfan Syndrome and Suffering from Stanford Type A Aortic Dissection during Pregnancy. Masui 2015;64:412-5.

50. Yang Z, Yang S, Wang F, et al. Acute aortic dissection in pregnant women. Gen Thorac Cardiovasc Surg 2016;64:283-5.

51. Kuperstein R, Cahan T, Yoeli-Ullman R, et al. Risk of Aortic Dissection in Pregnant Patients With the Marfan Syndrome. Am J Cardiol 2017;119:132-7.

52. Sayama S, Takeda N, Iriyama T, et al. Peripartum type B 
aortic dissection in patients with Marfan syndrome who underwent aortic root replacement: a case series study. BJOG 2017. [Epub ahead of print].

53. Meijboom LJ, Timmermans J, Zwinderman AH, et al. Aortic root growth in men and women with the Marfan's syndrome. Am J Cardiol 2005;96:1441-4.

54. Pacini L, Digne F, Boumendil A, et al. Maternal complication of pregnancy in Marfan syndrome. Int J Cardiol 2009;136:156-61.

55. Donnelly RT, Pinto NM, Kocolas I, et al. The immediate and long-term impact of pregnancy on aortic growth rate and mortality in women with Marfan syndrome. J Am Coll Cardiol 2012;60:224-9.

56. Hassan N, Patenaude V, Oddy L, et al. Pregnancy outcomes in Marfan syndrome: a retrospective cohort study. Am J Perinatol 2015;30:123-30.

57. Roman MJ, Pugh NL, Hendershot TP, et al. Aortic Complications Associated With Pregnancy in Marfan Syndrome: The NHLBI National Registry of Genetically Triggered Thoracic Aortic Aneurysms and Cardiovascular Conditions (GenTAC). J Am Heart Assoc 2016;5 . pii: e004052.

58. Katsuragi S, Ueda K, Yamanaka K, et al. Pregnancyassociated aortic dilatation or dissection in Japanese women with Marfan syndrome. Circ J 2011;75:2545-51.

59. Regitz-Zagrosek V, Blomstrom Lundqvist C, Borghi C, et al. ESC Guidelines on the management of cardiovascular diseases during pregnancy: the Task Force on the Management of Cardiovascular Diseases during Pregnancy of the European Society of Cardiology (ESC). Eur Heart J 2011;32:3147-97.

60. Groenink M, Lohuis TA, Tijssen JG, et al. Survival and complication free survival in Marfan's syndrome: implications of current guidelines. Heart 1999;82:499-504.

61. Sakaguchi M, Kitahara H, Seto T, et al. Surgery for acute type A aortic dissection in pregnant patients with Marfan syndrome. Eur J Cardiothorac Surg 2005;28:280-3; discussion 283-5.

62. Elkayam U, Goland S, Pieper PG, et al. High-Risk Cardiac Disease in Pregnancy: Part II. J Am Coll Cardiol 2016. [Epub ahead of print].

63. Svensson LG, Blackstone EH, Feng J, et al. Are Marfan syndrome and marfanoid patients distinguishable on longterm follow-up? Ann Thorac Surg 2007;83:1067-74.

64. Gott VL, Cameron DE, Alejo DE, et al. Aortic root replacement in 271 Marfan patients: a 24-year experience. Ann Thorac Surg 2002;73:438-43.

65. Meijboom LJ, Drenthen W, Pieper PG, et al. Obstetric complications in Marfan syndrome. Int J Cardiol 2006;110:53-9.

66. Curry RA, Gelson E, Swan L, et al. Marfan syndrome and pregnancy: maternal and neonatal outcomes. BJOG 2014;121:610-7.

67. Dietz HC. Marfan Syndrome. GeneReviews. Seattle, WA: University of Washington, Seattle, 2001.

68. Child AH. Marfan syndrome--current medical and genetic knowledge: how to treat and when. J Card Surg 1997;12:131-5; discussion 135-6.

69. Eldadah ZA, Grifo JA, Dietz HC. Marfan syndrome as a paradigm for transcript-targeted preimplantation diagnosis of heterozygous mutations. Nat Med 1995;1:798-803.

70. Simpson LL, Athanassious AM, D'Alton ME. Marfan syndrome in pregnancy. Curr Opin Obstet Gynecol 1997;9:337-41.

71. Milewicz DM, Dietz HC, Miller DC. Treatment of aortic disease in patients with Marfan syndrome. Circulation 2005;111:e150-7.

72. Baumgartner H, Bonhoeffer P, De Groot NM, et al. ESC Guidelines for the management of grown-up congenital heart disease (new version 2010). Eur Heart J 2010;31:2915-57.

73. Hiratzka LF, Bakris GL, Beckman JA, et al. 2010 ACCF/AHA/AATS/ACR/ASA/SCA/SCAI/SIR/STS/ SVM Guidelines for the diagnosis and management of patients with thoracic aortic disease. A Report of the American College of Cardiology Foundation/American Heart Association Task Force on Practice Guidelines, American Association for Thoracic Surgery, American College of Radiology,American Stroke Association, Society of Cardiovascular Anesthesiologists, Society for Cardiovascular Angiography and Interventions, Society of Interventional Radiology, Society of Thoracic Surgeons, and Society for Vascular Medicine. J Am Coll Cardiol 2010;55:e27-e129.

74. Kouchoukos NT, Dougenis D. Surgery of the thoracic aorta. N Engl J Med 1997;336:1876-88.

75. David TE. Aortic surgery in the Marfan syndrome. Adv Card Surg 2001;13:61-75.

76. Elkayam U, Bitar F. Valvular heart disease and pregnancy: part II: prosthetic valves. J Am Coll Cardiol 2005;46:403-10.

77. Boodhwani M, Andelfinger G, Leipsic J, et al. Canadian Cardiovascular Society position statement on the management of thoracic aortic disease. Can J Cardiol 2014;30:577-89.

78. Davies RR, Gallo A, Coady MA, et al. Novel measurement 
of relative aortic size predicts rupture of thoracic aortic aneurysms. Ann Thorac Surg 2006;81:169-77.

79. David TE, Feindel CM. An aortic valve-sparing operation for patients with aortic incompetence and aneurysm of the ascending aorta. J Thorac Cardiovasc Surg 1992;103:61721; discussion 622.

80. de Oliveira NC, David TE, Ivanov J, et al. Results of surgery for aortic root aneurysm in patients with Marfan syndrome. J Thorac Cardiovasc Surg 2003;125:789-96.

81. Kallenbach K, Baraki H, Khaladj N, et al. Aortic valvesparing operation in Marfan syndrome: what do we know after a decade? Ann Thorac Surg 2007;83:S764-8; discussion S785-90.

82. Elassy SM, Elmidany AA, Elbawab HY. Urgent cardiac surgery during pregnancy: a continuous challenge. Ann Thorac Surg 2014;97:1624-9.

83. Kapoor MC. Cardiopulmonary bypass in pregnancy. Ann Card Anaesth 2014;17:33-9.

84. John AS, Gurley F, Schaff HV, et al. Cardiopulmonary bypass during pregnancy. Ann Thorac Surg 2011;91:1191-6.

85. Pomini F, Mercogliano D, Cavalletti C, et al. Cardiopulmonary bypass in pregnancy. Ann Thorac Surg 1996;61:259-68.

86. Fattori R, Montgomery D, Lovato L, et al. Survival

Cite this article as: Goland S, Elkayam U. Pregnancy and Marfan syndrome. Ann Cardiothorac Surg 2017;6(6):642-653. doi: 10.21037/acs.2017.10.07 after endovascular therapy in patients with type B aortic dissection: a report from the International Registry of Acute Aortic Dissection (IRAD). JACC Cardiovasc Interv 2013;6:876-82.

87. Rios AS, Silber EN, Bavishi N, et al. Effect of long-term beta-blockade on aortic root compliance in patients with Marfan syndrome. Am Heart J 1999;137:1057-61.

88. Krishnamoorthy P, Garg J, Shah N, et al. Effect of beta-blockers on progressive aortic dilatation in patients with Marfan's syndrome. J Am Coll Cardiol 2015;65:A2106-A.

89. Alwan S, Polifka JE, Friedman JM. Angiotensin II receptor antagonist treatment during pregnancy. Birth Defects Res A Clin Mol Teratol 2005;73:123-30.

90. Suzuki T, Eagle KA, Bossone E, et al. Medical management in type B aortic dissection. Ann Cardiothorac Surg 2014;3:413-7.

91. Elefteriades JA, Farkas EA. Thoracic aortic aneurysm clinically pertinent controversies and uncertainties. J Am Coll Cardiol 2010;5 5:841-57.

92. Garcia-Bournissen F, Shrim A, Koren G. Safety of gadolinium during pregnancy. Can Fam Physician 2006;52:309-10.

93. Briggs GG, Freeman RK. Drugs in Pregnancy and Lactation. 10 ed. Philadelphia: Wolters Kluwer, 2015. 